\title{
Clinical and biological profiles of older adults aged 50 and over compared to those under 50 in people living with HIV attending Kinshasa University Teaching Hospital (DR Congo)
}

\author{
MMK Mbula1*, B Longo-Mbenza², HNT Situakibanza1, \\ GL Mananga ${ }^{3}$, JRR Makulo4, MM Longokolo', MN Mandina1, \\ NN Mayasi', MM Mbula5 ${ }^{5}$ B Bepouka1, GL Mvumbi ${ }^{6}$, \\ EN Amaela7, DN Tshilumba ${ }^{8}$, O Odio'1, BM Ekila1, A Nkodila1, \\ T Pindi ${ }^{1}$ and BBT Buasa ${ }^{6}$ \\ ${ }^{1}$ Infectious Diseases Service, Kinshasa University Teaching Hospital, DR Congo \\ ${ }^{2}$ Lomo University of Research, Kinshasa, Cardiology Service, Kinshasa University Teaching \\ Hospital, DR Congo \\ ${ }^{3}$ Neuro Psycho Pathological Center (CNPP), Kinshasa University Teaching Hospital, DR Congo \\ ${ }^{4}$ Nephrology Service, Kinshasa University Teaching Hospital, DR Congo \\ ${ }^{5}$ General Practitioner, Kinshasa, DR Congo \\ ${ }^{6}$ Department of Basic Sciences, Faculty of Medicine, University of Kinshasa, DR Congo \\ ${ }^{7}$ Kinshasa General Military Reference Hospital, Camp Kokolo, DR Congo \\ ${ }^{8}$ Higher Institute of Medical Techniques, Mbuyi-Mayi, Kasai-Oriental, DR Congo
}

\section{More Information}

*Address for Correspondence:

Mbula Mambimbi Marcel, Infectious Diseases Service, Kinshasa University Teaching Hospital, DR Congo, Email: marcelmbula@yahoo.fr

\section{Submitted: October 02, 2021 \\ Approved: October 27, 2021 \\ Published: October 28, 2021}

How to cite this article: Mbula MMK, LongoMbenza B, Situakibanza HNT, Mananga GL, Makulo JRR, et al. Clinical and biological profiles of older adults aged 50 and over compared to those under 50 in people living with HIV attending Kinshasa University Teaching Hospital (DR Congo). Int J Clin Virol. 2021; 5: 087-095.

DOI: 10.29328/journal.ijcv. 1001040

Copyright: (c) 2021 Mbula MMK, et al. This is an open access article distributed under the Creative Commons Attribution License, which permits unrestricted use, distribution, and reproduction in any medium, provided the original work is properly cited.

Keywords: HIVIAIDS; Older adults; Elderly PLWHIVs; Clinical and biological profiles; DR Congo

\section{D) Check for updates \\ (1) OPEn Access}

\section{Abstract}

Background: The survival of people living with HIV (PLWHIVs) is increased and Health systems will have to deal with the early-agingassociated medical conditions.

Objective: The objective of this study is to compare the clinical and biological profiles of PLWHIVs aged 50 and over and those aged less than 50 years.

Material and methods: This study conducted at Kinshasa University Teaching Hospital (KUTH) covers 6 years. The clinical and biological characteristics of PLWHIVs aged 50 and over were compared with those under 50 . Statistical analysis used the means \pm SD, the calculation of frequencies, Student's t-test and Chi-square.

Results: PLWHIVs aged 50 or over represented $35.1 \%$. Their average age was $58.0 \pm 4.8$ years. Women predominate among those under 50 and men among those 50 and over. Married people were more numerous ( $54 \%$ among those under 50 ). There were more unemployed (50\% of PLHIV under 50). Patients 50 years and older were significantly classified as WHO stage 4 with a high frequency of history of tuberculosis, genital herpes, high blood pressure, smoking, vomiting, hepatomegaly, moderate elevation of diastolic blood pressure (DBP) and sytolic blood pressure (SBP), tuberculosis and anemia.

Those under 50 had a significantly increased frequency of shingles, hepatitis B-hepatitis $\mathrm{C}$, headaches and more survivals.

The mean of $\mathrm{Hb}, \mathrm{HDL}-\mathrm{C}$, and $\mathrm{CD} 4 \mathrm{~s}^{+}$were significantly lower in patients 50 years and older, and urea, LDL-C, and ALAT levels were significantly higher.

Conclusion: The average age was higher from 50 years old. These PLWHIVs were more frequently in WHO stage 4 with more common TB and anemia. Their Hb, HDL-C, and CD4s+ levels were lower while their urea, LDL-C and ALAT levels were significantly elevated. 


\section{Introduction}

Since the use of HAART, PLWHIVs are living longer, healthier lives and have a better quality of life. Initially, when HIV infection was first described, PLWHIVs lived 1 to 2 years after diagnosis. Aging was therefore not a health problem of concern to health care providers [1]. Currently, when the diagnosis is made early, treatment is started in time according to WHO recommendations ("Test and Treat" strategy) [2]. This makes it possible to increase the survival of PLWHIVs and to test older adults who will be put on HAART. Some PLWHIVs have tested positive before age 50 and others after age 50 and over. In 2018, in the United States of America (USA) and dependent areas, 36\% of PLWHIVs (out of an estimate of 1.1 million) were aged 55 and over [1] and 51\% of them were aged 50 and over [3]. Among the newly diagnosed PLWHIVs in the same year $(37,968), 17 \%$ were aged 50 and over (1 in 6 new HIV diagnoses) and were male. Currently, in the USA, nearly half of people newly diagnosed with HIV infection are aged 50 and over [1,3-6]. Elderly PLWHIVs commonly suffer from several life-threatening illnesses and several health care factors delay the diagnosis and treatment of these patients Bhata, et al. [6], in a systematic review and metaanalysis, present some characteristics of HIV infection. They estimated the overall prevalence of HIV infection in elderly people at $15.79 \%$ and the viral suppression rate at $11.524 \%$. Very few of the elderly PLWHIVs were on HAART (38.643\%). The retention rate and mortality in this category of patients represent $12.76 \%$ and $6.15 \%$ respectively. For Bhata, et al. retention of older PLWHIVs in developing countries is high, but few have suppressed their viral load. For them, age is an indicator of clinical progression of the disease and that age 50 and over is an independent prognostic factor influencing clinical death [6]. With the increase in life expectancy, PLWHIVs will experience aging, particularly in those who are 50 years old and over. PLWHIVs under HAART who have suppressed their viral load will experience clinical features common to aging with multiple chronic diseases and age-related medical conditions, polypharmacy, changes in physical and cognitive capacities and increased vulnerability to stress [1,7-9]. The complications associated with this prolonged survival are medical pathologies associated with HIV that do not classify AIDS because the morbid conditions classifying AIDS are reduced because of HAART. HIV infection is accompanied by immune activation and chronic inflammation. This increases the risk of developing age-related conditions. Among the conditions associated with chronic inflammation, there are cardiovascular diseases (ischaemic heart disease), type 2 diabetes mellitus, lyphoma and certain cancers, lung diseases, osteoporosis, intracranial haemorrhage, HIV-associated neurocognitive disorders (HAND) [1,8,9]. Liver damage has also been observed. This includes hepatitis B and C. PLWHIVs present with severe health conditions unrelated to HIV early on. These conditions are accelerated, accentuated and caused by various socio-economic and lifestyle factors (tobacco use, excessive alcohol consumption, lack of physical activity and insufficient diet).

Women should include menopause and declining bone density [7].

Chronic inflammation has been shown to persist even with HAART.

HIV and its treatment affect the brain. More than 50\% of PLWHIVs have HAND. They present psychological distress, depression, deficits in attention, language and motor skills. Depression may interfere with adherence to HAART $[7,8]$.

According to the CDC, in the USA, 35\% of PLHIVs aged 50 and over are diagnosed with late-stage HIV (AIDS). They will face certain challenges including social isolation and concern. They are victims of stigma and discrimination. Their selfesteem drops. It has a negative impact on their life. This is one of the factors that will prevent them from disclosing their HIV status, not seeking treatment, or opting out of care $[1,7]$.

In Canada, Europe and Asia, the diagnosis of HIV infection in people 50 years of age and over is increasing [10-15].

In Africa, the number of PLWHIVs aged 50 years and over has also increased since the use of HAART which has reduced morbidity and mortality. Initially, The Joint United Nations Programme on HIV/AIDS (UNAIDS) paid little attention to the $50+$ age group. It was in 2006 that UNAIDS statistics began to take into account PLWHIVs over 49 years of age because a substantial proportion of PLWHIVs was part of this group. Studies carried out using Ugandan and South African data have shown an increase in the life expectancy of PLWHIVs $[16,17]$. Other studies have also mentioned the aging of the HIV epidemic in Africa, the comorbidities that can occur in PLWHIVs and the increase in life expectancy. This increase in the number of PLWHIVs will put a strain on the African health systems already weakened by the lack of means and qualified personnel for the care of the elderly [18-24]. There is hardly any data on the aging of the HIV epidemic in the DR Congo. Mandina, et al. have shown an association between hypovitaminosis D and aging in HIV/AIDS [25]. Collecting data relating to older PLWHIVs becomes urgent as their number is increasing and they have specific needs for their age group. Their physical, mental and social health needs must be understood by providers. The national AIDS and STI control program (PNLS) must develop and implement the health and social services required to take care of these patients.

The objective of this study is to compare the clinical and biological profiles of PLWHIVs aged 50 and over and those aged less than 50 years.

\section{Methods}

We carried out a cross-sectional study using a database of the service relating to a retrospective cohort. This study covers a period from January 1, 2008 to December 31, 2014. The 
patients selected are those attending the infectious diseases service of KTUH. This is a consecutive series of PLWHIVs followed in outpatient and inpatient care who are at least 18 years old. Clinical and laboratory data from PWLHIVs aged less than 50 years were compared to those 50 years and over.

The following parameters of interest were analyzed:

- Sociodemographic characteristics [Age, gender (male, female, transgender), profession (unemployed, state workers, junior company officer, liberal and other), religion (Catholics, protestants, revival churches and other), civil status (married, single, widower, divorced), level of study [primary level (1 to 6 years), secondary (1 to 6 years) and university level (superior institute and university)], socioeconomic level (low, medium, elevated), ethnicity [(Kongo and Ngala in West), Luba (in Center), and Swahili (in East)].

- The clinical [including opportunistic infections = OIs and other comorbidities (anaemia, Kaposi Diseases)] and biological characteristics of the study population. The diagnosis of oral candidiasis and shingles and genital herpes were clinical. Meningeal cryptococcosis was diagnosed by testing for a cryptococcus antigen, Indian ink and the detection of Cryptococcus neoformans by culture on sabouraud medium. For TB the diagnosis was made from the clinic, chest $\mathrm{x}$-ray, sputum ziehl and genExpert. Non-specific bacterial pneumonia has been clinically diagnosed along with chest $\mathrm{x}$-ray and clinical improvement under nonspecific antibiotic treatment.

- The vital issue (Alive, death, loss to follow).

- The evolution of $\mathrm{CD} 4 \mathrm{~s}^{+}$in relation to age.

- The biological characteristics of 2 categories of patients were evaluated. The analyzes carried out are shown in Table 1 and give the reference values of the various biological variables studied.

\begin{tabular}{|c|c|c|}
\hline $\mathbf{N}^{\circ}$ & Variable & Reference values \\
\hline 1 & $\mathrm{Hb}$ & 12.5 to $15 \mathrm{~g} / \mathrm{dL}$ for men and 10 to $15 \mathrm{~g} / \mathrm{dL}$ for women \\
\hline 2 & $\mathrm{Ht}$ & $38 \%$ to $52 \%$ for men and $32 \%$ to $45 \%$ for women. \\
\hline 3 & WBC & 4,000 to less than 10,000 cells $/ \mathrm{mm}^{3}$. \\
\hline 4 & LF: Neutrophils & $30 \%$ to $60 \%$ \\
\hline & Lymphocytes & $26 \%$ to $60 \%$ \\
\hline & Eosinophils & $0 \%$ to $12 \%$. \\
\hline 5 & $\mathrm{CD}_{4} \mathrm{~s}^{+}$ & From 410 to 1590 cells $/ \mathrm{mm}^{3}$ \\
\hline 6 & Urea & 10 to $42 \mathrm{mg} \%$. \\
\hline 7 & Creatinine & 0.5 to $1.2 \mathrm{mg} \%$ \\
\hline 8 & ASAT & 0 to $40 \mathrm{IU} / \mathrm{L}$ \\
\hline 9 & ALAT & 0 to $45 \mathrm{IU} / \mathrm{L}$ \\
\hline 10 & High TC & When value $>200 \mathrm{mg} / \mathrm{dL}$ \\
\hline 11 & Hypertriglyceridaemia & When TG > $150 \mathrm{mg} / \mathrm{dL}$ \\
\hline 12 & High LDL-C & When value $>130 \mathrm{mg} / \mathrm{dL}$ \\
\hline 13 & Low HDL-C & $\begin{array}{c}\text { if value }<40 \mathrm{mg} / \mathrm{dL} \text { for men and }<50 \mathrm{mg} / \mathrm{dL} \text { for } \\
\text { women }\end{array}$ \\
\hline
\end{tabular}

Hb: Haemoglobin; Ht: Haematocrit; WBC: White Blood Count; LF: Leucocyte Formula; CD4: Cluster of Differentiation four; ASAT: Aspartate Amino Tranferase; ALAT: Alanine Amino Transferase; TC: Total Cholesterol; LDL-C: Low Density Lipoprotein Cholesterol; HDL-C: High Density Lipoprotein Cholesterol

\section{Statistical analyzes}

The mean and standard deviation were calculated for continuous variables. For categorical variables, the frequency was calculated.

The comparisons were made using the means with Student's t- test and the proportions with the chi-square test.

\section{Ethical clearance}

The study is based on a retrospective cohort and used a deidentified database. The Helsinki ethical principles (respect for private life and confidentiality) were respected. This does not require informed consent and the opinion of an ethics committee.

\section{Results}

The frequency of PLHIVs aged 50 and over in this hospital population is $35.1 \%$. The mean age \pm SD of the patients was $45.7 \pm 11.1$ years in general. This mean age \pm SD was $38.9 \pm$ 6.9 in patients less than 50 years old and $58 \pm 4.8$ in those 50 years and older $(p<0,01)$ (Table $1 \mathrm{~A})$.

There is a predominance of the female sex $(63 \%$ of

\begin{tabular}{|c|c|c|c|c|}
\hline Variables & $\begin{array}{c}\text { All } \\
n=270\end{array}$ & $\begin{array}{c}<50 \text { ans } \\
n=175\end{array}$ & $\begin{array}{c}\geq 50 \text { ans } \\
n=95\end{array}$ & $p$ \\
\hline Age \pm SD & $45,7 \pm 11,1$ & $38,9 \pm 6,9$ & $58,0 \pm 4,8$ & $<0,001$ \\
\hline Sex & & & & $<0,001$ \\
\hline Male & $100(37,0)$ & $50(28,6)$ & $50(52,6)$ & \\
\hline Female & $170(63,0)$ & $125(71,4)$ & $45(47,4)$ & \\
\hline Civil status & & & & 0,001 \\
\hline Maried & $135(52,9)$ & $90(54,5)$ & $45(50,0)$ & \\
\hline Divorced & $45(17,6)$ & $30(18,2)$ & $15(16,7)$ & \\
\hline Single & $45(17,6)$ & $35(21,2)$ & $10(11,1)$ & \\
\hline Widower & $30(11,8)$ & $10(6,1)$ & $20(22,2)$ & \\
\hline Profession & & & & $<0,001$ \\
\hline Unemployed & $95(41,3)$ & $80(50,0)$ & $15(21,4)$ & \\
\hline State worker & $50(21,7)$ & $25(15,6)$ & $25(35,7)$ & \\
\hline Junior company officer & $15(6,5)$ & $10(6,3)$ & $5(7,1)$ & \\
\hline Liberal & $70(30,4)$ & $45(28,1)$ & $25(35,7)$ & \\
\hline Level of study & & & & 0,008 \\
\hline Primary & $15(9,4)$ & $5(4,8)$ & $10(18,2)$ & \\
\hline Secondary & $95(59,4)$ & $70(66,7)$ & $25(45,5)$ & \\
\hline University level & $50(31,3)$ & $30(28,6)$ & $20(36,4)$ & \\
\hline Religion & & & & 0,056 \\
\hline Catholic & $90(46,2)$ & $50(38,5)$ & $40(61,5)$ & \\
\hline Protestant & $20(10,3)$ & $15(11,5)$ & $5(7,7)$ & \\
\hline Revival churches & $55(28,2)$ & $45(34,6)$ & $10(15,4)$ & \\
\hline Other & $30(15,4)$ & $20(15,4)$ & $10(15,4)$ & \\
\hline Socioeconomic level & & & & 0,016 \\
\hline Medium & $90(85,7)$ & $60(92,3)$ & $30(75,0)$ & \\
\hline Low & $15(14,3)$ & $5(7,7)$ & $10(25,0)$ & \\
\hline Ethnicity & & & & 0,005 \\
\hline Kongo & $80(39,0)$ & $40(30,8)$ & $40(53,3)$ & \\
\hline Ngala & $40(19,5)$ & $25(19,2)$ & $15(20,0)$ & \\
\hline Luba & $60(29,3)$ & $45(34,6)$ & $15(20,0)$ & \\
\hline Swahili & $25(12,2)$ & $20(15,4)$ & $5(6,7)$ & \\
\hline
\end{tabular}

SD: Standard Deviation 
women). The sex ratio was 1,7 women to 1 man $(1,7 \mathrm{~F} / 1 \mathrm{H})$. In the group of patients younger than 50 years, the frequency of women was significantly higher than that of 50 years and older $(2,5 \mathrm{~F} / 1 \mathrm{M})$.

The single people were predominantly under the age of 50 years. Those aged 50 years and over had a higher frequency of widowers.

PLWHVs aged 50 years and over were more in the primary study level. Most of them had a low socioeconomic level $(p=0.016)$. Patients under 50 years were more unemployed compared to those 50 years and over.

The clinical characteristics are shown in Table 2.

Patients over 50 years of age have been significantly classified as WHO stage 4 . They had a high frequency of history

\begin{tabular}{|c|c|c|c|c|}
\hline Variables & $\begin{array}{c}\text { All } \\
n=270\end{array}$ & $\begin{array}{c}<50 \text { ans } \\
n=175\end{array}$ & $\begin{array}{c}\geq 50 \text { ans } \\
n=95\end{array}$ & $\boldsymbol{p}$ \\
\hline WHO Clinical Stage & & & & $<0,001$ \\
\hline Stage 1 & $27(10,0)$ & $27(15,4)$ & $0(0,0)$ & \\
\hline Stage 2 & $33(12,2)$ & $27(15,4)$ & $6(6,3)$ & \\
\hline Stage 3 & $83(30,7)$ & $49(28,0)$ & $34(35,8)$ & \\
\hline Stage 4 & $127(47,0)$ & $72(41,1)$ & $55(57,9)$ & \\
\hline \multicolumn{5}{|l|}{ Antecedents } \\
\hline TB & $60(22,2)$ & $30(17,1)$ & $30(31,6)$ & 0,006 \\
\hline Bacterial pneumoniae & $15(5,6)$ & $15(8,6)$ & $0(0,0)$ & - \\
\hline Cerebral toxoplasmosis & $5(1,9)$ & $0(0,0)$ & $5(5,3)$ & - \\
\hline Meningeal cryptococcosis & $20(7,4)$ & $20(11,4)$ & $0(0,0)$ & - \\
\hline Kaposi disease & $20(7,4)$ & $15(8,6)$ & $5(5,3)$ & 0,231 \\
\hline Oral candidiasis & $60(22,2)$ & $45(25,7)$ & $15(15,8)$ & 0,067 \\
\hline Shingle & $40(14,8)$ & $35(20,0)$ & $5(5,3)$ & 0,001 \\
\hline Enteritis & $10(3,7)$ & $5(2,9)$ & $5(5,3)$ & 0,249 \\
\hline Genital herpes & $15(5,6)$ & $5(2,9)$ & $10(10,5)$ & 0,011 \\
\hline Coinfection HBV-HCV & $30(12,8)$ & $25(16,7)$ & $5(5,9)$ & 0,012 \\
\hline HTA & $40(14,8)$ & $5(2,9)$ & $35(36,8)$ & $<0,001$ \\
\hline Diabetes mellitus & $5(1,9)$ & $0(0,0)$ & $5(5,3)$ & - \\
\hline Obesity & $10(3,7)$ & $5(2,9)$ & $5(5,3)$ & 0,249 \\
\hline Tobacco & $20(7,4)$ & $5(2,9)$ & $15(15,8)$ & $<0,001$ \\
\hline Alcohol & $55(20,4)$ & $40(22,9)$ & $15(15,8)$ & 0,110 \\
\hline \multicolumn{5}{|l|}{ Clinical signs on admission } \\
\hline Fever & $75(27,8)$ & $45(25,7)$ & $30(31,6)$ & 0,188 \\
\hline Weight loss & $125(46,3)$ & $75(42,9)$ & $50(52,6)$ & 0,079 \\
\hline Diarrhea & $240(88,9)$ & $160(91,4)$ & $80(84,2)$ & 0,057 \\
\hline Cough & $210(77,8)$ & $140(80,0)$ & $70(73,7)$ & 0,150 \\
\hline Vomiting & $235(87,0)$ & $145(82,9)$ & $90(94,7)$ & 0,003 \\
\hline Headache & $45(16,7)$ & $40(22,9)$ & $5(5,3)$ & $<0,001$ \\
\hline Conjunctival pallor & $55(20,4)$ & $35(20,0)$ & $20(21,1)$ & 0,478 \\
\hline Hepatomegaly & $15(5,6)$ & $5(2,9)$ & $10(10,5)$ & 0,011 \\
\hline Lateralization sign & $10(3,7)$ & $5(2,9)$ & $5(5,3)$ & 0,249 \\
\hline SBP & $120,7 \pm 18,2$ & $118,9 \pm 20,5$ & $124,1 \pm 12,5$ & 0,025 \\
\hline DBP & $77,8 \pm 13,8$ & $76,1 \pm 15,7$ & $80,9 \pm 8,3$ & 0,005 \\
\hline Weight & $61,7 \pm 15,7$ & $60,7 \pm 17,1$ & $63,6 \pm 12,1$ & 0,213 \\
\hline Pulse & $89,2 \pm 18,1$ & $93,5 \pm 16,5$ & $81,3 \pm 18,1$ & 0,000 \\
\hline Height & $1,66 \pm 0,09$ & $1,69 \pm 0,09$ & $1,62 \pm 0.06$ & 0,000 \\
\hline RR & $22,5 \pm 4,9$ & $22,4 \pm 4,9$ & $22,5 \pm 4,9$ & 0,924 \\
\hline BMI & $23,5 \pm 6,9$ & $22,7 \pm 8,0$ & $24,9 \pm 3,9$ & 0,108 \\
\hline
\end{tabular}

HTA: Hypertension; HBV: Hepatitis B Virus; HCV: Hepatitis C Virus; SBP: Systolic Blood Pressure; DBP: Diastolic Blood Pressure; RR: Respiratory Rate; BMI: Body Mass Index of TB, genital herpes, hypertension, and tobacco use. On the other hand, those under 50 years of age had a significantly high frequency of shingles and hepatitis B-hepatitis C.

Regarding clinical signs on admission, patients 50 years of age and over had a high frequency of vomiting, hepatomegaly. Headaches were more common in patients younger than 50 years old. The means of SBP, DBP were significantly higher in patients 50 years and older.

The table 3 indicates the comorbidities.

Patients 50 years and over had a higher incidence of TB and anemia.

The biological characteristics are shown in the Table 4.

The mean $\mathrm{Hb}$, HDL-C, and $\mathrm{CD} 4 \mathrm{~s}^{+}$were significantly lower in patients 50 years and older. Urea, LDL-C, and ALAT levels were significantly higher in this category of patients.

\section{CD4s ${ }^{+}$count according to age}

The figure 1 indicates the $\mathrm{CD} 4 \mathrm{~s}^{+}$count according to age.

Below $200 \mathrm{CD}^{4} \mathrm{~s}^{+}$, the frequencies were similar between the 2 groups. For $\mathrm{CD} 4 \mathrm{~s}^{+}$counts between 200 and 499 cells $/ \mu \mathrm{L}$,

\begin{tabular}{|c|c|c|c|c|}
\hline Comorbidities & $\begin{array}{c}\text { All } \\
n=270\end{array}$ & $\begin{array}{c}<50 \text { ans } \\
n=175\end{array}$ & $\begin{array}{c}\geq 50 \text { ans } \\
n=95\end{array}$ & $p$ \\
\hline TB & $50(18,5)$ & $20(11,4)$ & $30(31,6)$ & $<0,001$ \\
\hline Oral candidiasis & $50(18,5)$ & $30(17,1)$ & $20(21,1)$ & 0,264 \\
\hline Anaemia & $65(24,1)$ & $35(20,0)$ & $30(31,6)$ & 0,025 \\
\hline Shingle & $20(7,4)$ & $15(8,6)$ & $5(5,3)$ & 0,231 \\
\hline Meningeal cryptococcosis & $15(5,6)$ & $15(8,6)$ & $0(0,0)$ & - \\
\hline Cerebral toxoplasmosis & $5(1,9)$ & $0(0,0)$ & $5(5,3)$ & - \\
\hline Kaposi Disease & $10(3,7)$ & $10(5,7)$ & $0(0,0)$ & - \\
\hline Genital herpes & $5(1,9)$ & $0(0,0)$ & $5(5,3)$ & - \\
\hline Enteritis & $5(1,9)$ & $0(0,0)$ & $5(5,3)$ & - \\
\hline
\end{tabular}

Table 4: Biological characteristics.

\begin{tabular}{|c|c|c|c|c|c|}
\hline Variables & $n$ & All & $<50$ ans & $\geq 50$ ans & $p$ \\
\hline $\mathrm{Hb}$ & 215 & $9,3 \pm 2,9$ & $9,7 \pm 2,9$ & $8,7 \pm 2,7$ & 0,013 \\
\hline $\mathrm{Ht}$ & 160 & $29,4 \pm 8,0$ & $29,8 \pm 7,5$ & $28,6 \pm 9,0$ & 0,395 \\
\hline WBC & 210 & $6339,5 \pm 334,8$ & $6301,7 \pm 370,2$ & $6423,8 \pm 240,0$ & 0,808 \\
\hline Neutrophils & 200 & $59,3 \pm 13,7$ & $59,3 \pm 12,6$ & $59,3 \pm 16,2$ & 0,993 \\
\hline Lymphocytes & 200 & $36,9 \pm 13,3$ & $36,5 \pm 11,7$ & $37,9 \pm 16,4$ & 0,484 \\
\hline Glycaemia & 100 & $93,5 \pm 21,1$ & $91,8 \pm 16,7$ & $98,4 \pm 30,7$ & 0,179 \\
\hline Urea & 205 & $31,6 \pm 19,4$ & $28,7 \pm 15,8$ & $38,6 \pm 24,9$ & 0,001 \\
\hline Creatinine & 205 & $1,14 \pm 0,16$ & $1,07 \pm 0,17$ & $1,32 \pm 0,75$ & 0,122 \\
\hline Total Cholesterol & 134 & $153,9 \pm 53,9$ & $156,7 \pm 55,9$ & $147,0 \pm 48,9$ & 0,346 \\
\hline LDL-C & 115 & $79,9 \pm 45,4$ & $71,2 \pm 41,9$ & $99,6 \pm 47,6$ & 0,002 \\
\hline HDL-C & 105 & $60,2 \pm 42,7$ & $70,2 \pm 48,2$ & $40,2 \pm 15,5$ & 0,001 \\
\hline Triglyceride & 120 & $133,8 \pm 61,6$ & $137,7 \pm 70,0$ & $125,9 \pm 39,8$ & 0,326 \\
\hline ASAT & 165 & $36,9 \pm 33,8$ & $34,8 \pm 3,7$ & $42,4 \pm 2,5$ & 0,200 \\
\hline ALAT & 165 & $33,6 \pm 25,8$ & $28,9 \pm 22,6$ & $46,0 \pm 29,7$ & 0,000 \\
\hline CD4s ${ }^{+}$ & 270 & $256,9 \pm 23,5$ & $290,4 \pm 27,3$ & $195,4 \pm 12,1$ & 0,001 \\
\hline
\end{tabular}

Hb: Haemoglobin; Ht: Haematocrit; WBC: White Blood Cells; LDL-C: Low Density Lipoprotein Cholesterol; HDL-C: High Density Lipoprotein Cholesterol; ASAT: Aspartate Amino Transferase; ALAT: Alanine Amino Transferase. CD4: Cluster of Differentiation. The mean $\mathrm{Hb}, \mathrm{HDL}-\mathrm{C}$, and $\mathrm{CD} 4 \mathrm{~s}^{+}$were significantly lower in patients 50 years and older. Urea, LDL-C, and ALAT levels were significantly higher in this category of patients. 
the most common category of patients was 50 years and over. No cases have been observed in people 50 years and over with $500 \mathrm{CD} 4 \mathrm{~s}^{+}$and above.

\section{Vital outcome of patients}

Vital outcome of patients is shown in figure 2.

There are more survivors among those under 50 , but the difference is not statistically significant.

\section{Discussion}

This study compared the clinical and biological characteristics of PLWHIVs aged 50 years and over with those under 50 years.

This study shows that more than one in three PLWHIV was aged 50 and over in this hospital series. The average age of PLWHIVs aged 50 and over was high. There were more widowers, people with a primary education and a low socioeconomic level for PLWHIVs aged 50 years and over.

There was a predominance of women in the general study population and in patients under 50 years of age.

There are more widowers, people with primary education and a low socioeconomic level for PLWHIVs aged 50 and over. There was a predominance of females in the study population in general and in patients under 50 years of age.

TB and hypertension were frequently encountered in the history of PLWHIVs while the history of hepatitis B and C was

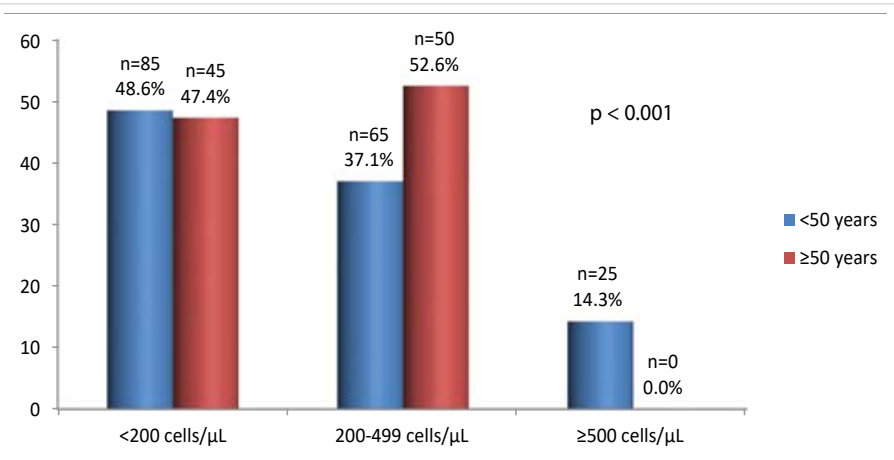

Figure 1: CD4s+ count according to age.

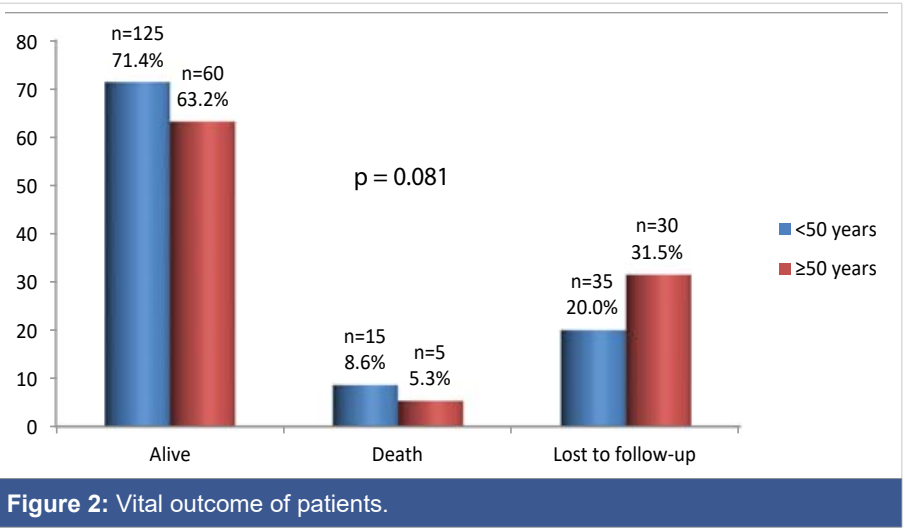

more noted in patients under 50 years of age. The greater number of WHO stage 4 patients are found in this group of patients as well as high average of DBP. TB and anemia were common in this category of patients. Their average levels of $\mathrm{Hb}, \mathrm{HDL}-\mathrm{C}$, and $\mathrm{CD} 4 \mathrm{~s}^{+}$were low. On the other hand, high values of urea, LDL-c and ALAT were observed.

\section{Fréquency of PLWHIVs, sociodemographic and economic characteristics}

The frequency of PLWHIVs aged 50 and over in this study was $35.1 \%$ of all PLWHIVs. If we exclude the deceased and the lost to follow-up, with the use of HAART, this number will increase more and more and will pose problems related to the advancement in age and the geriatric syndrome. Despite the limited number of patients in this series, this statistic gives a trend in the aging of the epidemic in our context. This increasing trend in the number of PLWHIVs aged 50 and over with HIV infection shows that it is not only sexually active young people and young adults who become infected. From the age of 50, some people are still sexually active. This group of people can be exposed to the risk of infection with HIV if they do not follow the prevention recommendations of the national AIDS and STI control program. We also observe an improvement in the quality of life and survival of PLWHIVs since the use of HAART. This explains this increase in the number of PLWHIVs who are at least 50 years old.

In general, the proportion of PLWHIVs is increasing in the world. Statistics relating to the aging of the epidemic vary in the literature. In 2014, in the gap report, UNAIDS estimated the elderly PLWHIVs at 4.2 million [26]. This proportion was estimated globally at 5.7 million in 2016; $80 \%$ of these PLWHIVs lived in low- or intermediate- resource countries [7]. This trend was expected to continue, particularly in lowor intermediate- resource countries, during the year 2020. CDC statistics show that in 2018, PLWVIHs accounted for $17 \%$ of new reported HIV-infections. Among the PLWHIVs in the USA and their dependents, one in 6 PLWHIVs was aged 50 and over [1,3]. Currently, in the USA this proportion is nearly $50 \%$ of newly diagnosed PLWHIVs. Batha, et al. [6] found in a systematic review and meta-analysis of 28 studies $15.79 \%$ of pooled prevalence of HIV in elderly. In Canada, in 2018, the number of older PLWHIVs was $22.5 \%$ of diagnosed with HIV infection [27]. It is estimated that in Canada, by 2025, one in six infected adults will be 50 years of age and over [12]. In the UK, statistics from 2018 show that one in five people have been diagnosed late with HIV infection. And two in five accessed HIV care when they were 50 or older [28].

African studies have also shown that the life expectancy of PLWHIVs has increased in South Africa, Uganda, Rwanda and is approaching that of people not infected with HIV. The number of PLWHIVs in Sub-Saharan Africa triples in the coming years to reach 10 million by 2040 [16,17,23,30]. In 2015, in Rwanda, the study population of Nsanzimana, et al. 
included $10.4 \%$ of PLWHIVs aged 50 and over [30]. Taylor, et al. in Ghana, in 2018, had 20\% of PLWHIVs over the age of 50 [31]. In the series by Diallo, et al. the proportion of older PLWHIVs was $10.3 \%$ [33]. It's the same in Asia: in Madi, et al. in India, the proportion of PLWHIVs was $15.27 \%$ [34].

Mean age \pm SD of older PLWHIVs in our series was 58.4 \pm 4.8 years. This average age is high and shows that the life expectancy of PLWHIVs is increasing.The median age of PLWHIVs in the series by Diallo, et al. was 54.5 years (IQR: 52 57.4 ), in the elderly people [33]. The mean age \pm SD in the work of Madi, et al. was $55.9 \pm 6.1$ years [34]. In Nigeria, Dakum, et al. had a median age of 51.1 years (IQR: 52-60) [35]. Age is considered to be an indicator of the clinical progression of HIV infection [6]. It is an independent prognostic factor influencing the progression of the disease. When the diagnosis is made from the age of 50, life expectancy is reduced. Seroconversion in old age lowers the endurance rate, increases mortality and the rapid development of AIDS [6]. Advanced age makes PLWHIVs and the elderly uninfected with HIV susceptible to numerous pathogens and vulnerable to infectious and noninfectious diseases (cardiovascular pathologies, hypertension, diabetes mellitus). This impacts the adherence to HAART, which drops.

In this series, the female sex is more represented among PLWHIVs under 50, with a statistically significant difference. Probably after 50 years more of them die or be lost to followup. Women are vulnerable to HIV infection. Their vulnerability is physiological, economic, etc. In the USA, in 2018, people newly diagnosed with HIV were predominantly female [3]. In Nsanzimana, et al. women represented $63.8 \%$ overall [30]. The percentage of women aged 50 and over has not been determined. For Durvasula, the prevalence and incidence of HIV infection in older women will increase as the number of PLWHIVs increase [32]. The sex-ratio (Male/female) in Diallo's series [33] was 1,2. Madi's PLWHIVs series included $68.4 \%$ of men [34]. In the study by Dakum, the female sex represented 53\% [35].

Widowers were more numerous among older PLWHIVs. Patients in this series were included when scaling up was not yet effective. Elderly people who are frail and probably have more comorbidities are more prone to die. This may explain the high number of widowers in this socio-demographic category of patients.

Singles were more numerous among patients under the age of 50. Generally, in society, married couples are more numerous among adults. From the age of 50, it is more likely to meet the bride and groom in the communities. In Rwanda, married or living with partners represented $47.9 \%$ while divorced and single people represented $22.3 \%$ and $11.1 \%$ respectively [30]. The proportions of married people differ depending on the series: $59.6 \%$ for Diallo, et al. [33] and $92.5 \%$ for Madi, et al. [34]. In the series by Dakum, et al. married people represented $71 \%$, widowers, separated couples and divorced 24\% [35].

In this study, the level of primary education was predominant in older PLWHIVs. In Diallo, et al. illiterate represented 57.6\%. The Dakum, et al. [35] series had enrolled $33 \%$ of secondary level PLWHIVs followed by $29 \%$ of primary level patients, $19 \%$ of post-secondary level PLWHIVs; $19 \%$ of the study population consisted of illiterate people.

The most frequent socioeconomic level of patients in this study was low. The study population is a hospital population. It is difficult to draw a conclusion on these aspects relating to the socioeconomic level. People without a job are found the most frequent among those under 50 in this series. It is among young people and young adults that one usually finds the unemployed and the self-employed who organize their own activities. Among those over 50, we often find people with a job. In the Diallo's study [33], 57\% of patients had a professional occupation and $64.17 \%$ of patients in the Madi, et al. series were employed.

Christians, especially Catholics, are more numerous in our series. This corresponds to the distribution of church members in the DR Congo where Catholics are more numerous [36].

\section{Clinical characteristics}

Overall, the PLWHIVs in this series were classified as stages 3 and 4 . These are probably patients who were diagnosed late or who went through other health structures. It is not uncommon to meet PLWHIVs who opt for treatment with traditional healers or who are content only with spiritual care. They ultimately consult late in modern medicine when their health deteriorates significantly due to advanced HIV infection. However, advanced HIV infection has a poor prognosis. It is in these medical conditions that appear the TB or meningeal cryptococcosis responsible for death in many PLWHIVs. In the general population, many people do not know their HIV status. They are seroignorant. Even when they have been at risk of contracting HIV, they refuse to be tested for HIV. Which delays care.

The group of older PLWHIVs included more WHO stage 4 patients. Which means they're probably taken care of late. During aging, immunity deteriorates. This can make an elderly person infected with HIV more vulnerable, especially when they refuse the care of modern medicine and if they are cured by traditional medicine or only by "prayer".

Age is an indicator of disease progression and age 50 and over is an independent prognostic factor influencing death. In Nsanzimana, et al. stages 1 and 2 accounted for 54.7\% [30]. Stage 4 was poorly represented. The study by Diallo, et al. [33] included $59.2 \%$ of patients classified as WHO clinical stages 3 and 4. The series by Madi, et al. [34] and Dakum, et al. [35] predominated in WHO clinical stage I. These proportions represented $64.17 \%$ of patients and $47 \%$ respectively. 
TB has been frequently encountered in the history of pateints in our series, especially in PLWHIVs aged 50 and over. Given the mutual effects of these two pathologies, it is important to look for TB in PLWHIVs and HIV infection in tuberculosis patients. This requires the establishment of a circuit of care for PLWHIVs that takes these two conditions into account. Hence, the importance of setting up a care system that provides a full range of care (one-stop shop). In healthcare structures where the two conditions are treated in different departments, close collaboration must be established between the departments in which the patients are treated.

A history of hypertension was reported by many of the PLWHIVs in this study. Healthcare providers should look for it in any PLWHIV. HIV infection is characterized by chronic systemic inflammation and intense immune activation. This inflammation affects various organs of the body and exacerbates other comorbidities including cardiovascular disease. HIV infection also accelerates atherosclerosis. Hence, the possible increase in cardiovascular risk.

Different symptoms and signs have been encountered in our patients. They are classic and common to many PLWHIVs. Very few of them were statistically significant. These include vomiting, increased DBP in PLWHIVs aged 50 and over, and headaches in PLWHIVs under 50. The management of these patients must take particular account of the blood pressure disturbances that may be observed during HIV infection.

\section{Comorbidities}

In this study, TB, anemia and hypertension were the comorbidities that were statistically significant. As stated in the section on medical history, HIV-TB coinfection should be tested for every healthcare provider-patient encounter. TB is a leading cause of death in PLWHIVs worldwide [37,38]. It is important to screen for pathologies occurring in people of advanced age in PLWHIVs. TB represented $17 \%$ in Rwanda in 2015 [30] and 26,67\% at Madi series [34].

Anemia, usually multifactorial in PLWHIVs, must be addressed and corrected. Among PLWHIVs, anaemia is common $[39,40]$.

As for hypertension, it must be screened for. Nonpharmacological and pharmacological measures must be put in place. The mean of DBP is significantly higher in older PLWHIVs in our series. SBP was also elevated in PWLHIVs 50 years and older, but this elevation in blood pressure was not statistically significant. Cardiovascular and metabolic pathologies appear in the elderly. With age, cardiovascular pathologies including hypertension appear in elderly people $[1,9,15,23]$. In the series by Diallo, et al. and Dakum, et al. hypertension represented $31.7 \%$ and $21 \%$ of patients, respectively. At Madi, et al. hypertension was encountered in $77.5 \%$ of cases [34].
All these comorbidities must be monitored in collaboration with the various expertise in the various fields.

Patients under 50 had a higher frequency of shingles and viral hepatitis $\mathrm{B}$ and $\mathrm{C}$. We have not found an explanation justifying the high frequency of these pathologies in young people.

\section{Biological charactéristics}

In this series, the means of $\mathrm{Hb}, \mathrm{HDL}-\mathrm{C}$ and $\mathrm{CD} 4 \mathrm{~s}^{+}$were significantly low in older PLWHIVs. Anemia is common in HIV infection as we mentioned above. It is of multifactorial origin. It gets worse as the HIV infection progresses. Anemia is responsible for morbidity and mortality in PLWHIVs. However, it can be treated. It is therefore recommended that healthcare providers always obtain an $\mathrm{Hb}$ level as soon as the PLWHIVs are enrolled in the healthcare structure. In DR Congo, the blood count is classified in the basic examinations to be carried out at PLWHIVs.

Low HDL-C in older PLWHIHs means that HIV infection is progressing and the risk of inheriting is increasing. This risk increases with age. In our series, the low HDL-C level in PLWHIVs aged 50 and over is statistically significant. This category of patients is already at risk due to advanced age and HIV infection. Usually they have a high viral load and a low $\mathrm{CD} 4 \mathrm{~s}^{+}$count. These patients are at risk of atherosclerosis and cardiovascular pathologies. The lipid profile must therefore be included in the pre-treatment assessment in settings where this examination may be available or if the patient can perform it.

The low $\mathrm{CD}_{4} \mathrm{~s}^{+}$count indicates late-stage HIV infection and late management. When the $C D 4 s^{+}$counts were $200 / \mu \mathrm{L}$, there was no difference between the two groups of patients. Between 200 and $499 \mathrm{CD}_{4} \mathrm{~s}^{+} / \mu \mathrm{L}$, the number of PLWHIVs was higher in PLWHIVs aged 50 and over and the difference was statistically significant. In Nsanzimana, et al. in Rwanda, the $\mathrm{CD} \mathrm{s}^{+}$count was less than $200 \mathrm{CD} 4 \mathrm{~s}^{+} / \mu \mathrm{L}$ in $23.3 \%$; $38.3 \%$ of PLWHIVs had a CD4s ${ }^{+}$count between 200 and $499 \mathrm{CD}^{+} \mathrm{s}^{+}$ $\mu \mathrm{L}$. These results have been presented globally and do not distinguish between the under 50 and 50 and over categories [30].

In patients 50 years and older, urea, LDL-C, and ALAT levels were significantly higher. For renal function, it will be necessary to complete the creatinine dose balance and calculate the glomerular filtration rate. Other explorations must be carried out in collaboration with the nephrology team including the urine dipstick, renal biopsy etc. This is because kidney function usually impaired in HIV infection and at an advanced stage of the disease, especially in patients who are naive to HAART, due to the HIV per se or the drugs used to treat opportunistic infections (IOs). HAART has also been implicated for certain drugs used in combination therapy.

In HIV-related dyslipidemias, LDL-C abnormalities have 
been described. Its values can be high and participate in the occurrence of atherosclerosis responsible for cardiovascular disease. In HIV-related dyslipidemias, LDL-C abnormalities have been described. Its values can be high and participate in the occurrence of atherosclerosis responsible for cardiovascular disease. In our series, it occurs particularly in PLWHIVs aged 50 and over. Due to their age, these patients are at risk of developing cardiovascular disease.

In HIV infection, liver damage can occur. PLWHIVs can present with viral hepatitis B or C. OIs and drugs used during HIV infection can also be the basis of liver damage. This may explain the disruption of transaminases.

These various modifications require additional studies with a larger study population.

Survival of PLWHIVs was greater in patients less than 50 years old. However, this difference was not statistically significant. In a meta-analysis, Pooralajal, et al. study AIDS survival rate and mortality among PLWHIVs. This team finds that the majority of HAART-naive patients die within 2 years of the onset of AIDS [42].

\section{Conclusion}

The aging trend of PLWHIVs can be seen in this study by their high average age.

The female sex predominates in the category of PLWHIVs under 50 years old.

The patients included in this study were predominantly in WHO stages 3 and 4 . Those aged 50 and over were the largest number in stage 4.

TB and hypertension were the most common medical history among 50-year-old PLWHIVs.

dparticularly in PLWHIVs 50 years of age and older. The biological disturbances concerned Hb, HDL-C, LDL-C, urea ALAT and CD $4 \mathrm{~s}^{+}$

\section{Perspectives}

This study leads to prospects including those of setting up a unit for the management of medical conditions (clinical and biological) specific to PLWHIVs aged 50 and over. It should be run by a multidisciplinary team trained in geriatrics and HIV (infectiologists, psychologists, psychiatrists, cardiologists, sociologists, medical doctors, pharmacists, nurses, oncologists, pharmacologists) and other experts specializing in chronic diseases occurring during aging. This team will be responsible for managing the health conditions associated with the early aging observed during HIV infection: changes in physical appearance, cognitive abilities and increased vulnerability to stress.

This will require the training of identified providers in geriatric care, taking into account physical and mental health.
Those selected must be trained in research (Epidemiology, research methodology and holistic care of elderly PLWHIVs). The specific needs of PLWHIVs aged 50 and over in our community should be identified.

\section{References}

1. HIV.gov. Aging with HIV. https://www.hiv.gov/hiv-basics/living-wellwith-hiv/taking-care-of-yourself/aging-with-hiv

2. WHO. Treat all people living with HIV, offer antiretrovirals as additional prevention choice for people at "substantial" risk. https://www.who.int/ mediacentre/news/releases/2015/hiv-treat-all-recommendation/en/

3. CDC. HIV and older Americans. https://www.cdc.gov/hiv/group/age/ olderamericans/index.html

4. CDC. Diagnoses of HIV infection in the United States and dependent areas, 2018 (updated). HIV Surveillance Report. 2020; 31.

5. CDC. Estimated HIV incidence and prevalence in the United States, 2014-2018. HIV Surveillance Supplemental Report. 2020; 25. http://www.cdc.gov/hiv/library/reports/hiv-surveillance.html

6. Bhatta M, Nandi S, Dutta N, Dutta S, Saha MK. HIV Care Among Elderly Population: Systematic Review and Meta-Analysis. AIDS Res Hum Retroviruses. 2020; 36: 475-489.

PubMed: https://pubmed.ncbi.nlm.nih.gov/32027170/

7. Autenrieth CS, Beck EJ, Stelzle D, Mallouris C, Mahy, et al. Global and regional trends of people living with HIV aged 50 and over : Estimates and projections for 2000-2020. PloS ONE. 2020; 13: e0207005. PubMed: https://pubmed.ncbi.nlm.nih.gov/30496302/

8. Negredo E, Back D, Blanco José-Ramón, Blanco J, Erlandson KM, et al. Aging in HIV-Infected Subjects: A New Scenario and a New View. BioMed Res Int. 2017; 2017: 5897298.

PubMed: https://pubmed.ncbi.nlm.nih.gov/29430462/

9. Wing EJ. HIV and aging. Int J Infect Dis. 2016; 53: 61-68. PubMed: https://pubmed.ncbi.nlm.nih.gov/27756678/

10. Tavoschi L, Gomes Dias J, Pharris A, EU/EEA HIV Surveillance Network. New HIV dignoses among adults aged 50 years or older in 31 European countries, 3004-15: an analysis of surveillance data. Lancet HIV. 2017; 4: e514-521.

PubMed: https://pubmed.ncbi.nlm.nih.gov/28967582/

11. Seeley J. HIV diagnosis increasing in older adult in Europe. Lancet 2017; 4: e480-e481.

PubMed: https://pubmed.ncbi.nlm.nih.gov/28967581/

12. Sok P. Older Persons with HIV in Canada. J Infect Dis Epidemiol. 2019; 5: 084.

13. Haddad N, Robert A, Popovic $\mathrm{N}$ et al. Newly diagnosed cases of HIV in those aged 50 years and older and those less than 50: 2008-2017. Can Commun Dis Rep. 2019; 45: 283-288. PubMed: https://pubmed.ncbi.nlm.nih.gov/31755877/

14. McMillan JM, Krentz H, John Gill M, Hogan DB. Managing HIV infection in patients older than 50 years. CMAJ 2018; 190: E1253 -1258. PubMed: https://pubmed.ncbi.nlm.nih.gov/30348740/

15. Puhr RM, Kumarasamy N, Penh Sun L, Ng OT, Nguyen KV, et al. HIV and Aging: Demographic Change in the Asia-Pacific Region. J Acquir Immune Defic Syndr. 2017; 74: e146-e148.

PubMed: https://pubmed.ncbi.nlm.nih.gov/28267699/

16. Mills EJ, Bakanda C, Birungi J, Chan K, Ford N, et al. Life expectancy of persons receiving combination antiretroviral therapy in low-income countries: a cohort analysis from Uganda. Ann Intern Med. 2011; 155 209-216.

PubMed: https://pubmed.ncbi.nlm.nih.gov/21768555/

17. Hontelez JA, Lurie MN, Newell ML, Bakker R, Tanser F, et al. Ageing with HIV in South Africa. AIDS. 2011; 25: 1665-1673. PubMed: https://pubmed.ncbi.nlm.nih.gov/21681056/ 
18. Negin J, Gumming RG. HIV infection in older adults in sub-sahran Africa: extrapoling from existing data. Bulletin of the World Health Organization. 2010; 88: 847-853.

PubMed: https://www.ncbi.nlm.nih.gov/pmc/articles/PMC2971515/

19. Hontelez JAC, de Vlas SJ, Baltussen R, Newell ML, Bakker R, et al. The impact of antiretroviral treatment on the age composition of the HIV epidemic in sub-Saharan Africa. AIDS. 2012; 26 (Suppl 1): S19-S30. PubMed: https://pubmed.ncbi.nlm.nih.gov/22781175/

20. Bendavida E, Fordc N, Mills EJ. HIV and Africa's elderly: the problems and possibilities. AIDS. 2012; 26 (Suppl 1): S85-S91.

PubMed: https://pubmed.ncbi.nlm.nih.gov/22781181/

21. Mpondo BCT. HIV Infection in the Elderly: Arising challenges. J Aging Res. 2016; 2016: 2404857.

PubMed: https://pubmed.ncbi.nlm.nih.gov/27595022/

22. Mills EJ, Rammohan A, Awofso N. Ageing faster with AIDS in Africa. Lancet. 2011; 377: 1131-1133.

PubMed: https://pubmed.ncbi.nlm.nih.gov/21126759/

23. Siedner MJ. Aging, Health, and Quality of Life for Older People Living With HIV in Sub-Saharan Africa: A Review and Proposed Conceptual Framework. J Aging Health. 2019; 31: 109-138.

PubMed: https://pubmed.ncbi.nlm.nih.gov/28831864/

24. Reniers G, Blom S, Calvert C, Martin-Onraet A, Herbst AJ, et al Trends in the burden of HIV mortality after roll-out of antiretroviral therapy in KwaZulu-Natal, South Africa: an observational community cohort study. Lancet HIV. 2017; 4: e113-e121.

PubMed: https://pubmed.ncbi.nlm.nih.gov/27956187/

25. Mandina NM, Longo Mbenza B, Renzaho A. Hypovitaminosis D, Aging, HIV Infection, HAART, and Other Cardiovascular Risk Factors in Patients from Kinshasa, DR Congo, Central Africa.

26. UNAIDS. People aged 50 years and older. https://www.unaids.org/ sites/default/files/media_asset/12_Peopleaged50yearsandolder.pdf

27. Haddad N, Robert A, Weeks A, Popovic A, Siu W, et al. HIV in CanadaSurveillance Report, 2018. Can Commun Dis Rep. 2019; 45: 304-312. PubMed: https://pubmed.ncbi.nlm.nih.gov/32167090/

28. National AIDS Trust. HIV in the UK statistics-2018. PubMed: https://www.nat.org.uk/about-hiv/hiv-statistics

29. Eduardo E, Lamb MR, Kandula S, Howard A, Mugisha V, et al Characteristics and Outcomes among Older HIV-Positive Adults Enrolled in HIV Programs in Four Sub-Saharan African Countries. PLoS ONE. 2014; 9: e103864.

PubMed: https://pubmed.ncbi.nlm.nih.gov/25075743/

30. Nsanzimana S, Remera E, Kanters S, Chan K, Forrest JI, et al. Life expectancy among HIV-positive patients in Rwanda: A retrospective observational cohort study. Lancet Glob Health. 2015; 3: e69-e177. PubMed: https://pubmed.ncbi.nlm.nih.gov/25701995/

31. Taylor J, Ossei PPS, Agyeman-Duah E, Baah E, Fenteng EA, et al Socio-Demographic Characteristics of People Living with HIV/
AIDS at the Komfo Anokye Teaching Hospital, Ghana: A Five-Year Retrospective Study. Acta Sci Med Sci. 2018; 2: 42-47.

32. Durvasula R. HIVIAIDS in Older Women: Unique Challenges, Unmet Needs. Behav Med. 2014; 40: 85-98.

PubMed: https://pubmed.ncbi.nlm.nih.gov/25090361/

33. Diallo I, Meda N, Oue'draogo S, Poda A, Hema A, et al. Profiles of Elderly People Infected with HIV and Response to Antiretroviral Treatment in Burkina Faso: A Retrospective Cohort Study. J Int Assoc Provid AIDS Care. 2017; 16: 405-411.

PubMed: https://pubmed.ncbi.nlm.nih.gov/28571520/

34. Madi D, Ramakrishnan N, Unnikrishnan B, Ramapuram J, Achappa B, et al. Clinicoepidemiological Profile of Elderly PLHIV Attending a Tertiary Care Center in South India. J Int Assoc Provid AIDS Care. 2017; 16: 620-623.

PubMed: https://pubmed.ncbi.nlm.nih.gov/29187076/

35. Dakum P, Avong YK, Odutola MK, Okuma J, Kayode GA, et al. Cohort profile: the Nigerian HIV geriatric cohort study. BMC Public Health. 2020; 20: 1797.

PubMed: https://pubmed.ncbi.nIm.nih.gov/33243227/

36. Democratic Republic of the Congo 2018 international religious freedom report. Disponible à partir de. https://www.state.gov/wp-content/ uploads/2019/05/CONGO-DEM-REP-2018-INTERNATIONALRELIGIOUS-FREEDOM-REPORT.pdf

37. Cahill S, Valadéz R. Growing older with HIVIAIDS: new public health challenges. Am J Public Health. 2013; 103: e7-e15. PubMed: https://pubmed.ncbi.nlm.nih.gov/23327276/

38. Granich R, Akolo C, Gunneberg C, Getahun H, Williams P, et al Prevention of Tuberculosis in People Living with HIV. CID. 2010; 50: S215-S222.

PubMed: https://pubmed.ncbi.nlm.nih.gov/20397951/

39. Harding BN, Whitney BM, Nance RM, Ruderman SA, Crane HM, et al Anemia risk factors among people living with HIV across the United States in the current treatment era: a clinical cohort study. BMC Infect Dis. 2020; 20: 238.

PubMed: https://pubmed.ncbi.nlm.nih.gov/32197585/

40. Jaganath D, Walker AS, Ssali F, Musiime V, Kiweewa F, et al. HIVassociated anemia after 96 weeks on therapy: determinants across age ranges in Uganda and Zimbabwe. AIDS Res Hum Retroviruses. 2014; 30: 523-530.

PubMed: https://pubmed.ncbi.nIm.nih.gov/24506102/

41. Cardoso SW, Torres TS, Santini-Oliveira M, Marins LMS, Veloso VG, et al. Aging with HIV: a practical review. Braz J Infect Dis. 2013; 17: 464-479.

PubMed: https://pubmed.ncbi.nlm.nih.gov/23711587/

42. Poorolajal J, Hooshmand E, Mahjub H, Esmailnasab N, Jenabi E. Survival rate of AIDS disease and mortality in HIV-infected patients: a meta-analysis. Public Health. 2016; 139: 3-12.

PubMed: https://pubmed.ncbi.nlm.nih.gov/27349729/ 